\title{
Remotely sensed ore mineralization potentials in Ramand altered region, north of Iran
}

\author{
Abolfazl Ezzati ${ }^{1, ~}$, Reza Mehrnia ${ }^{2}$, Kimiya Ajayebi ${ }^{1}$ \\ ${ }^{1}$ Department of Geology, Islamic Azad University, Science and Research Branch, Tehran, Iran \\ ${ }^{2}$ Department of Geology, Payam Noor University, Tehran, Iran
}

Email address:

Ezzatiabollfazl@gmail.com (A. Ezzati),_R_Mehrniya@pnu.ac.ir(R. Mehrnia), Kimiya.ajayebi@kiau.ac.ir (K. Ajayebi)

To cite this article:

Abolfazl Ezzati, Reza Mehrnia, Kimiya Ajayebi. Remotely Sensed Ore Mineralization Potentials in Ramand Altered Region, North of Iran. American Journal of Civil Engineering. Special Issue: Research and Practices of Civil Engineering in Developing Countries.

Vol. 3, No. 2-2, 2015, pp. 18-23. doi: 10.11648/j.ajce.s.2015030202.14

\begin{abstract}
In some regions the main geological occurrences contain igneous pyroclastics formations such as rhyodacite and rhyolithic tuffs. An extended region with dominant alterations has been detected by remote sensing techniques for sampling purposes according to field observation activities. Enhancement of alterations has been done in Ramand region after applying a Crosta-based selective principle component analysis technique on ETM photomaps. Advanced Silicification haloes are most important evidence indicate to Base and Precious metals potentials in postmagmatic environments. For identifying the Silica content and related variations in epithermal systems, Crosta technique is adequate. This method introduces to recognition some clay and iron-oxides aggregations as the main part of gold bearing hydrothermal alterations in prospected regions. Concluded photomaps of which signals have been improved by mathematical analysis contained number of unique digital numbers related to mineralization potentials in Ramand region, Qazvin province, Iran.
\end{abstract}

Keywords: Remote Sensing, Crosta Technique, Silicic Alteration, Ramand

\section{Introduction}

Remote Sensing is a modern technology which without physical contacts with the phenomenon, we are able to measure and analyze spectral characteristics. Not only determining the alteration zones (and variations), but also separating mineralization anomalies is an important application of this technology as well. remote sensing techniques allows the identification of a large area with high accuracy, high speed and low cost.

Ore deposits are often produced by fluid flow processes that alter the mineralogy and chemistry of the country rock. A diversity of previous researches has proved the reliability of multispectral data analysis in the field of alteration detection [1]. Many ore deposits are first detected in the field by the recognition of hydrothermally altered host rocks, and are typically zonally distributed. Economic mineralization is often produced by fluid processes that substantially alter the mineralogy and chemistry of the host rocks. This alteration can produce distinctive assemblages of minerals that vary according to the location, degree, and longevity of those flow processes. When exposed to the surface of the Earth this alteration can sometimes be mapped at a zonal pattern [2]. By using remote sensing techniques these zones can be detected in a regional scale. In this study, Processing was performed on the ETM satellite imagery data of the Ramand area to map spectral signatures associated with the hydrothermal alterations. Ramand region in North-West of Iran is an importance region for, presence of good mineralization of, copper, lead, zinc and valuable metals such as Gold and Silver.

\section{Spectral Optimization by IHS Filtering}

In other to have primary display of the area, the boundary of layers and lineaments in ETM image are detected by using Intensity Hue Saturation (IHS) filter. This filter is a high-pass quality filter that despite other ENVI filters, relates to the intensity and quality. However, it is not relevant to DN values. This filter is used to optimize the image quality and separate the geological layers from alterations zones by ENVI 4.7. The advantage of this filter is to identify geological phenomenon specially faults structures [3]. In figure 2 the $\operatorname{RGB}(7,4,1)$ is 
filtered by IHS. It enhances and separates the different designations. lithological units better not revise any of the current

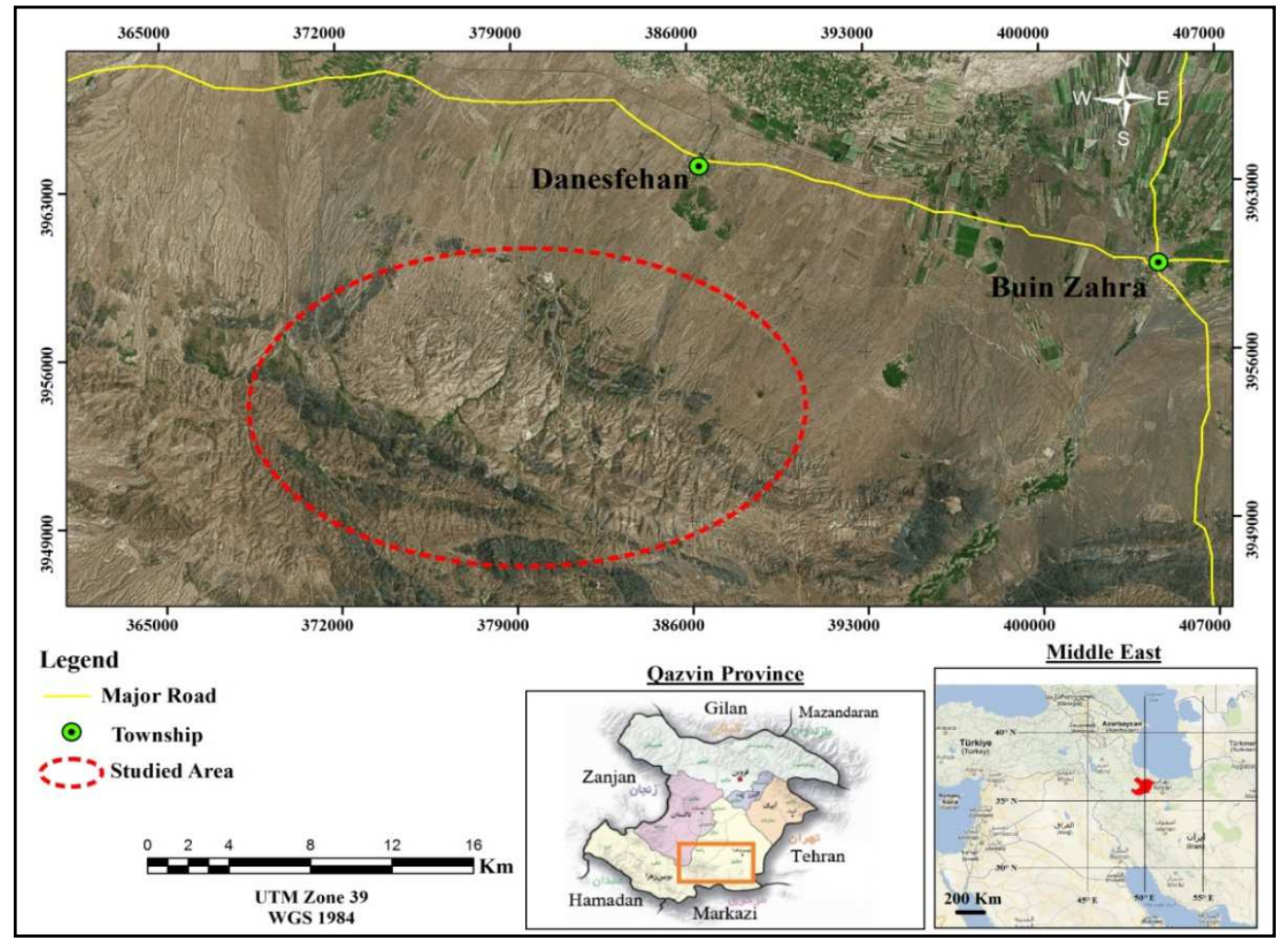

Figure 1. Study area

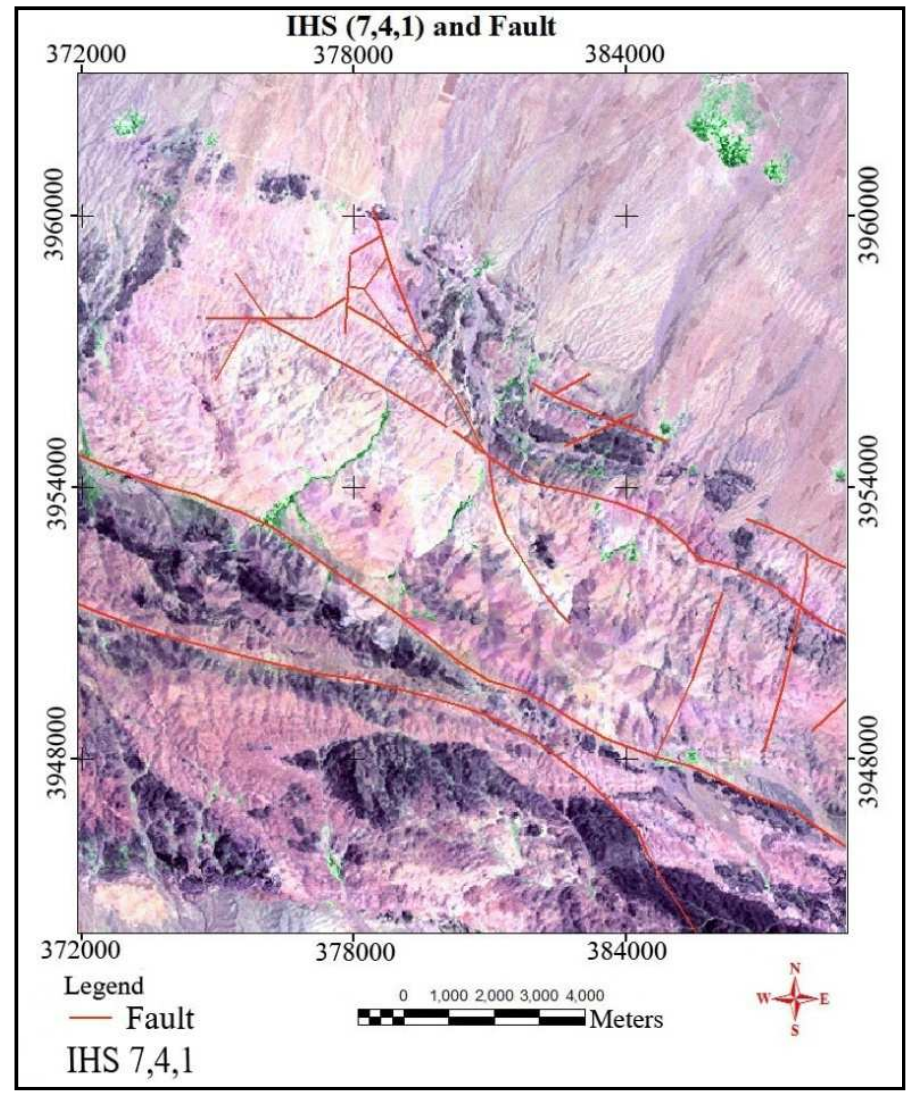

Figure 2. Enhancement of lineaments and boundary layers by IHS Filtering. 


\section{Implementation of Crosta Technique (Crosta PCA) for Enhancement of Alterations in Ramand Region}

The principal component transformation is a multivariate statistical technique that selects uncorrelated linear combinations (eigenvector loadings) of variables in such a way that each successively extracted linear combination or principal component (PC) has a smaller variance. The main aim of PC analysis is to remove redundancy in multispectral data. Principal component analysis is widely used for mapping of alteration in metallogenic provinces. Crosta technique is also known as feature oriented principal component selection. Through the analysis of the eigenvector values it allows identification of the principal components that contain spectral information about specific minerals, as well as the contribution of each of the original bands to the components in relation to the spectral response of the materials of interest [4].

According to present experiences and previous studies and also geological structure of region, appropriate bands for PCA analysis can be recognized.

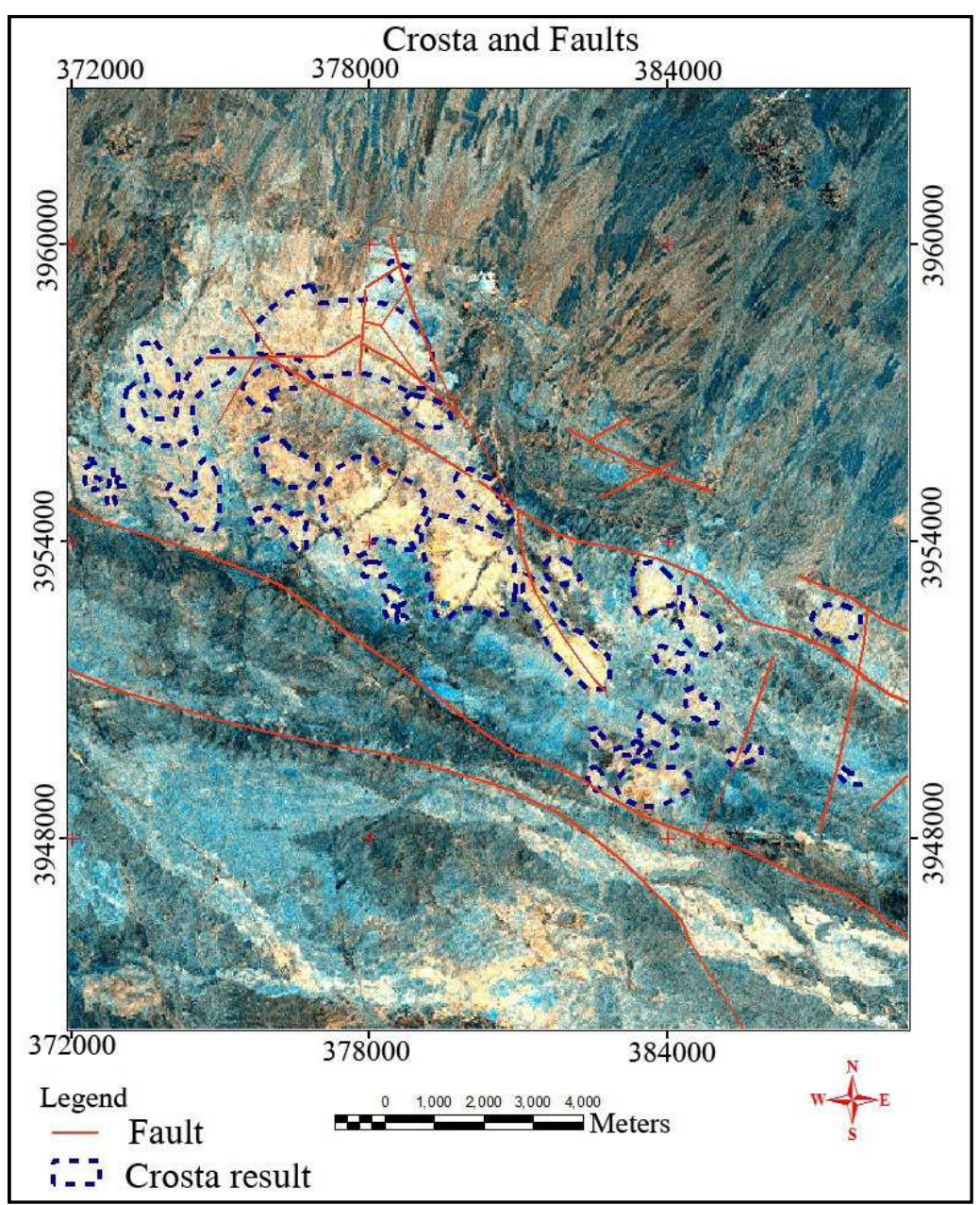

Figure 3. Hydrothermal Alterations according to Crosta PCA

In this method, reducing of the bands usually increases the probable mapping of definite processes according to discriminations between Eigen values (principal components-PC) [5]. Hydroxyl-bearing minerals are important because of their abundance in the alteration zones. Crosta technique defines the nature of alteration halos surrounding most of magmatic intrusions. Selective 7,5,4,1 ETM bands for mapping hydroxyls and selective 5,4,3,1 bands for mapping iron oxides have been proposed. The component analysis results of the first selections known as F-series and the second known as H-series. Studying Eigenvector of $\mathrm{F}$ and $\mathrm{H}-\mathrm{Series}$, the PC4 values made the most differential spectrums for revealing iron oxides and clayey minerals respectively (Table1 \& 2).

Applying Band Math technique caused adding $\mathrm{H}$ to $\mathrm{F}$ components for obtaining the new $\mathrm{H}+\mathrm{F}$ spectrums. RGB visible panels were constructed by these components as: $R=H$, $\mathrm{G}=\mathrm{H}+\mathrm{F}$ and $\mathrm{B}=\mathrm{F}$ for mapping hydrothermal alterations within yellowish-buff to orange colors of photomap (fig. 3).

A Selective Principle Component Analysis (SPCA) technique for identifying clay + iron oxide aggregation has been used and correlated with geochemical haloes for introducing young (Neogene) alteration facies related to epithermal mineralization processes in Ramand region. 
Table 1. The result of PCA for Enhancing Iron oxides

\begin{tabular}{lllll}
\hline Eigenvector & Band 1 & Band 3 & Band 4 & Band 5 \\
\hline PC 1 & 0.44759 & 0.597438 & 0.33271 & 0.57623 \\
PC 2 & -0.0279 & 0.635341 & 0.7262 & 0.261136 \\
PC 3 & -0.7294 & 0.045967 & -0.2202 & 0.646037 \\
PC 4 & 0.51656 & 0.487131 & -0.5599 & 0.427087 \\
\hline
\end{tabular}

Table 2. The result of PCA for Enhancing Hydroxyls.

\begin{tabular}{lllll}
\hline Eigenvector & Band 1 & Band 4 & Band 5 & Band 7 \\
\hline PC 1 & 0.47284 & 0.354945 & 0.61472 & 0.522072 \\
PC 2 & -0.1644 & 0.784691 & 0.07611 & 0.592812 \\
PC 3 & 0.8517 & 0.270296 & 0.4443 & -0.06449 \\
PC 4 & 0.15489 & 0.430365 & 0.64726 & -0.6098 \\
\hline
\end{tabular}

\section{Detection of Siliceous Facies Using Crosta Technique}

Crosta PCA is a recently developed technique for identifying alteration halos related to magmatic hydrothermal activities. This technique was proposed for the first time by Crosta and Moore (1989) [6], to indicate a specific purpose as a lighter pixel than the other phenomenon, in one of the principal component images. This is an improved technique for revealing hydrothermal alterations containing iron oxides

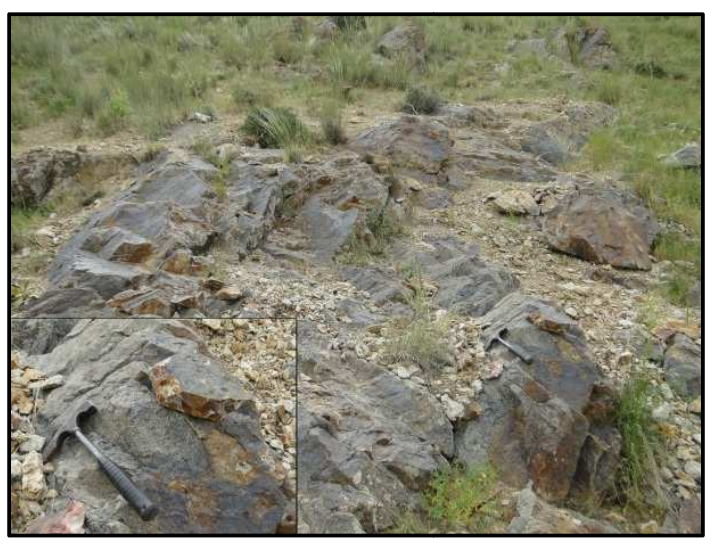

Figure 4. Jasperoid facies in the study area (see to the South West).

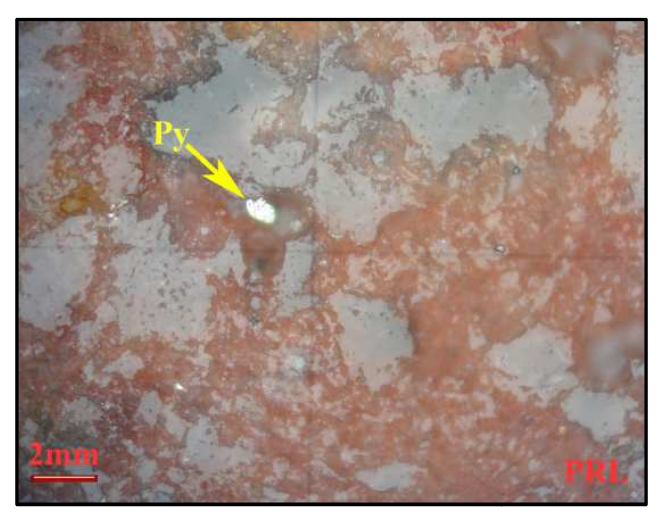

Figure 5. The higher values of iron oxides cause to red colors of matrix. ( probably presence of jasperoid). and clayey matrixes with hydroxyl ions combinations mineralogicaly [7]. In practice, numbers of aggregated halos have close relationships with hydrothermal systems. Therefore it can be determined by Crosta technique. In addition, due to large amount of paragenesis of silica mineralization, the electromagnetic responses of Crosta photomap are coincided with clay, iron oxides and silicification aggregations in this region. Our field observations "Fig. 4", plus instrumental (X-ray) and micrographic studies "Fig. 5", confirmed the reality of remotely sensed mineralization content in close associations with quartz, illite and jarosite paragenesis "Table 3", [8]. It means that, for the first time in Silica bearing facies, a Crosta based technique has been carried out for separating Si-alterations successfully.

In a prone area of hydrothermal deposits with large scale amounts of siliceous and iron oxide mineralization, Crosta technique can be easily introduced these areas among the hydrothermal alteration halos.

Table 3. X-ray result (Zarazma Mineral Studies Company).

\begin{tabular}{llll}
\hline Sample & Major Phase & Minor Phase & $\begin{array}{l}\text { Trace } \\
\text { Phase }\end{array}$ \\
\hline M37 & Quartz,Muscovite-Illite & Albite, Natrojarosite & - \\
M38 & Quartz, Illite & Orthoclase, Jarosite & Kaolinite \\
\hline
\end{tabular}

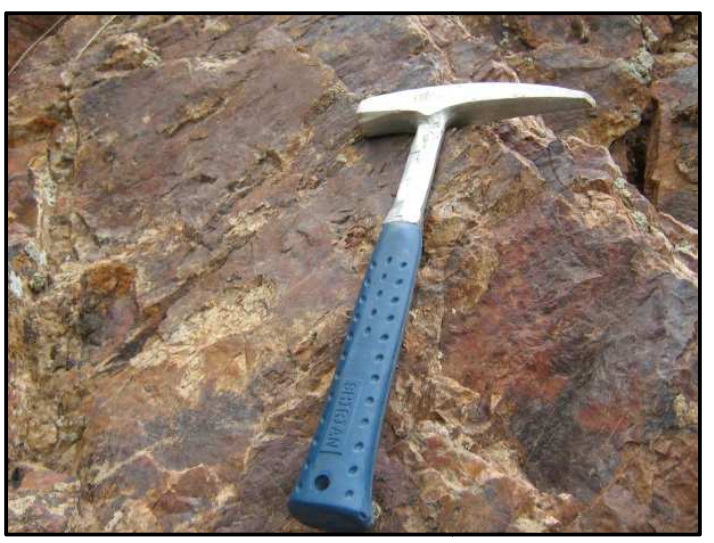

\section{Laboratory Studies}

Ore Microscopy and Petrographic studies have been well done after polished and thin sections preparation for focusing on mineralogical peculiarities of the samples. Figure 6 shows two micrographs indicate to paragenesis of available ore minerals (right) with nonmetallic aggregations as gangue traces (left). Pyrite and Hematite are important known mineralization at the surface of remotely sensed alteration (figure 6 - right). Also a massive silicified texture (fine grained) has been intruded by quartz and Fe-hydroxides according to petrographic evidences (figure 6- left). From mineralogical points of view, a massive Silica facies in paragenetic association with Fe-Oxide and Fe-Sulfide 
minerals have enough potential for increasing in gold traces anomalies. Therefore an atomic absorption analysis (AA) has been well done and summarized for Au analysis in table 4 .

As depicted, Au-grade varies between 131-145 ppb in adjacent of alteration occurrences which are mostly contained by argillic-silicific sequences. Individual shiny pyrites with bright appearance have additional reflections (comparing with pale types) and therefore selected for detailed quantitative analysis by Scanning Electron Microscopy (SEM).

Both mineralogical analytical evidences indicate to this fact that Ramand altered region not only has potentials for basics but considered as gold-bearing prospect according to SEM

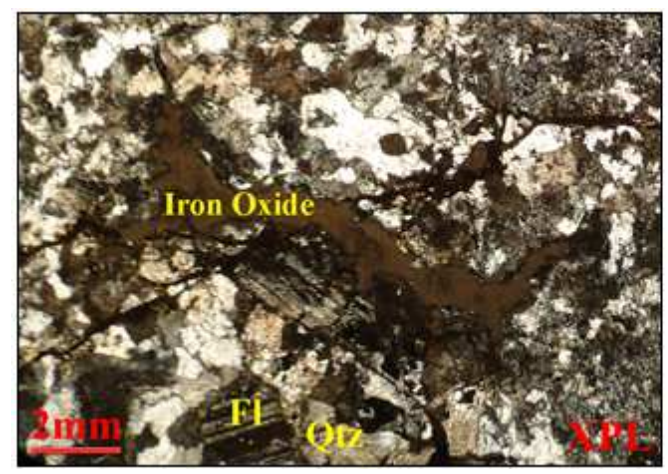

performances.

Increasing in Silica content has a direct relationship with pyrite and invisible gold traces associate with quartz-agate veinlets in post magmatic differential stages of hydrothermal environments [9].

Table 4. Atomic Absorption Analysis (AA) result for Ramand Au-bearing sample. (Zarazma Mineral Studies Company).

\begin{tabular}{lllll}
\hline Sample & M 28 & M 37 & M 31 & M 22 \\
\hline $\mathrm{Au}(\mathrm{ppb})$ & 131 & 133 & 125 & 145 \\
\hline
\end{tabular}

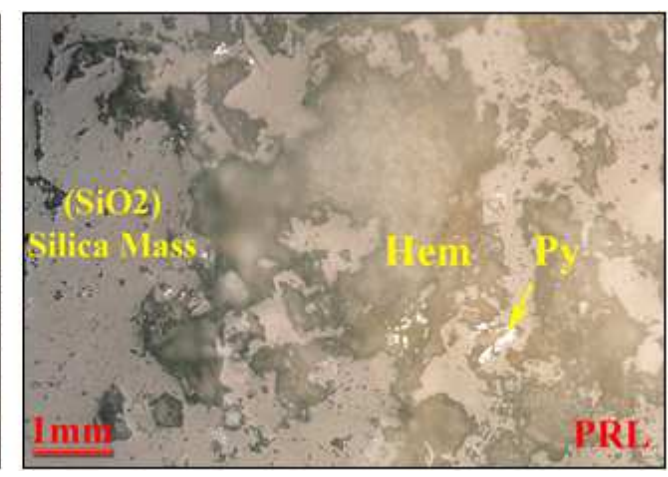

Figure 6. Ore microscopy (right) and ore petrography (left) results for remotely sensed altered samples- Ramand region. Right: two main ores are Hematite and Pyrite. Left: Silica masses plus quartz and feldspars are common gangue minerals in gold-bearing samples.

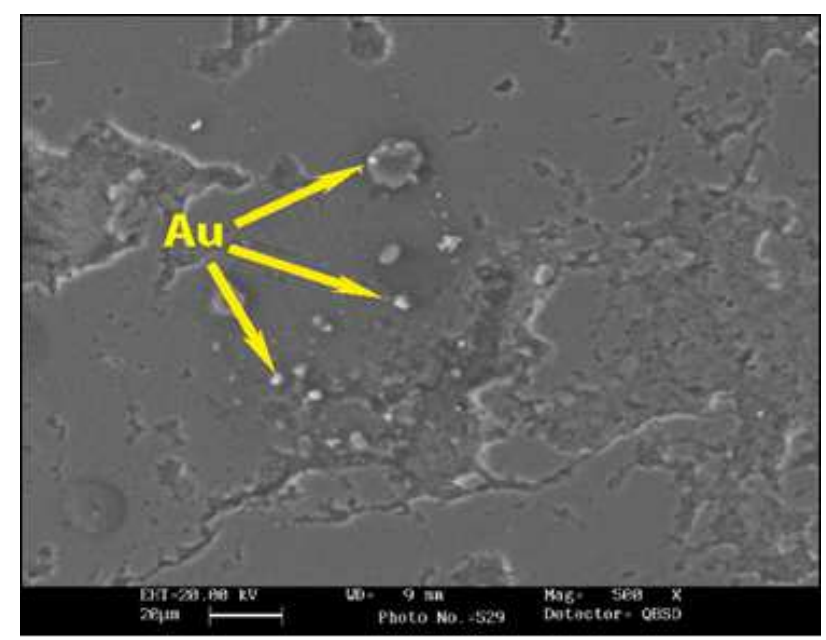

Figure 7. Shiny appearances in gold particles (Zarazma Mineral Studies Company).

\section{Discussion and Conclusions}

This research study focused on extended altered regions in Ramand mineralized prospects by processing ETM images according to Crosta technique. An aggregated alteration containing clay and iron oxides has been identified due to investigations. Sampling and instrumental analysis results showed that a clayey matrix within silica based mineralization is dominant in this region. Also our thin section studies have been well done and confirmed the hydrothermal origination of ore bearing solutions in a post magmatic environment.

From remote sensing points of view, Ramand prospected regions have enough potentials for epithermal mineralization because of extending number of solution related alterations on surfaces and existing evidence which indicate continuous alterations in depth of region. Therefore, a deep investigation on altered features and corresponding mineralization processes are highly recommended for further exploration activities in future with emphasizing on precious metals accumulations in the silica veinlets.

\section{References}

[1] AN. Rensz, "Remote Sensing For the Earth Sciences," John Wiley \& Sons, USA, 1999.

[2] G. Ferrier, K. White, G. Griffiths, R. Bryant, M. Stefouli, "The mapping of hydrothermal alteration zones on the island of Lesvos,Greece using an integrated remote sensing dataset," National Journal of Remote Sensing, ISSN 0143-1161, 2001.

[3] R. K. Vincent, "Fundamentals of Geological and Enviromental Remote Sensing," 1st edition Prentice Hall, 131p, (1997).

[4] H. Kaufman, "Mineral exploration along the Agaba-Levant structure by use of TM-data concepts, processing and results," International Journal of Remote Sensing, 1630-1658, 1998.

[5] W. P. Loughlin, "Principal Component Analyses for Alteration Mapping," Photogrammetric Engineering and Remote Sensing, Vol. 57, pp. 1163_1169, 1992.

[6] A. P. Crosta, J. Moore, "Enhancement of Landsat Thematic Mapper imagery for residual soil mapping in SW Minais Gerais State," Proceedings of the Seventh ERIM Thematic Conference: Remote Sensing for Exploration Geology, pp. 1173-1187, Brazil, 1989. 
[7] S. R. Mehrnia, "Using fractal filtering technique for processing ETM data as criteria for evaluating of Au-indices in north-west of Iran," 13th Australian Remote Sensing Conference, Canberra, Australia, 2006.

[8] A. Ezzati, R. Mehrnia, K. Ajayebi, "Detection of Heydrothermal potential zones using remote sensing satellite data in Ramand region Qazvine Province Iran," Journal of Tethys, vol. 2, pp. 93-100, April 2014.

[9] G. Morison, "AMIRA Project, Revised version : Evaluating of Gold Mineralization Potentials in Queensland Epithermal Systems," Queensland J.C Univ. press, Queensland, Australia, 249 p, 2003. 